Manuscript ID ZUMJ-2010-1993 (R3)

DOI

10.21608/zumj.2020.48238.1993

ORIGINAL ARTICLE

\title{
Impact of biologics drugs adherence on treatment outcomes and work productivity of Al Sharqia Governorate patients with Ankylosing Spondylitis
}

\author{
Manal Abdou Ali Yoyssef ${ }^{1 *}$, Dina Sameh Mohamed Elrefay ${ }^{2}$ \\ 1: Assistant professor of Rheumatology and Rehabilitation Medicine , Faculty of medicine -Zagazig University - \\ Egypt \\ 2: Lecturer of industrial medicine and occupational health , Faculty of medicine -Zagazig University -Egypt
}

*Corresponding author:
Manal Abdou Ali Yoyssef
Assistant professor of
Rheumatology and
Rehabilitation Medicine -
Faculty of medicine -Zagazig
University -Egypt
E
mail:dr.manal2004@yahoo.com

Submit Date: 2020-11-04

Revise Date: 2020-11-22

Accept Date: 2020-12-02

\begin{abstract}
Background: to improve ankylosing spondylitis (AS) treatment outcomes by clarifying the impact of biological medication adherence on their treatment outcomes, quality of life and work productivity. Methods: Sixty -six patients with AS were included according to eligibility criteria recruited from Rheumatology and Rehabilitation department at Zagazig University Hospitals(ZUH) and insurance hospital. Patients characteristics are collected. Biologics medication adherence was evaluated by the Compliance Questionnaire on Rheumatology (CQR). Disease activity and treatment response outcome measures were recorded at base line of biologics, after 6 month and after one year. Results: Insurance, education, employment and early diagnosis are the modifiable factors which can increase adherence to biologics drugs in adherent cases ASDAS CRP, and ASDAS ESR were significantly decreased after 6 months and highly significantly decreased after 12 months. BASFI \& BASMI were significantly decrease after 12 months , frequency of overall work and activity impairment was decreased after 6 months but after 12 months the decrease became significant with percent of reduction in both more than 50\%. Also AS quality of life (ASQOL) significant decreased after 6 months and 12 months. In non -adherent there was a significance increase in ASQOL score after 12 months. Conclusion: Biological therapy adherence leads to control disease activity confirmed by percentage of change in activity parameters after 6 months and highly significant change after 12 months of follow up especially BASMI in addition to improvements of work productivity and activity impairment and overall health -related quality of life, even in non -adherent who gain partial improvement.
\end{abstract}

Keywords: Ankylosing Spondylitis; biologic drugs adherence; treatment outcomes; work productivity.

\section{INTRODUCTION}

nkylosing spondylitis (AS), it is an
lautoimmune disease and type of
Spondyloarthropathy (SpA) that mainly
involves spine joints, sacroiliac joints and
paraspinl soft tissues, as ligaments and tendons.

Loosing of flexibility due to fusion of spine was seen in chronic advanced cases because of calcification and fibrosis resulting from the inflammation. There are also extra -articular manifestations, such as acute anterior uveitis and inflammatory bowel disease In addition to 
clinical manifestations including mainly back pain and progressive spinal rigidity as well as inflammation of the hips, shoulders and peripheral joints [1].

AS typically affects people at the most productive time in their lives. Pain, morning stiffness, and functional impairment reduce the quality of life (QoL) and decrease the ability to perform normal occupational activities, resulting in considerable socioeconomic burden for patients and society [2].

Early diagnosis and effective treatment of AS is possible with technological and scientific development [1].

When conventional treatment has been of limited benefit, the introduction of biological therapy must be a next step forward in improving most extra -articular manifestations, the quality of life, activity, metrology and functionality, in patients with AS [3].

World Health Organization (WHO) defined adherence as "the degree of agreement between person's behavior and the healthcare provider's agreed recommendations" [4]. The lack of adherence in chronic treatments is a traditional problem that compromises their effectiveness and can result in the worsening of the disease [5].

Now, biologics is covered by insurance agencies, treatment at state expense, or charities for failed conventional treatment or indicated cases of uveitis or other system affection.

Although biologic therapy is widely used now for uncontrolled or unsatisfied AS patients treated by traditional drugs, Most of the available data comes from other countries, As example Arturi et al [6], evaluated compliance with pharmacological treatment in AS, Tolu et al [7] studied medication adherence in Turkish patients with AS, Ji et al [8] evaluate effectiveness of subcutaneous tumor necrosis factor inhibitors .Work outcomes evaluated by van der Burg et al [9] An Egyptian study Sallam et al[10]assessed HRQoL in AS patients relation to clinical features, disease activity and radiographic damage.

To our knowledge, no studies have assessed adherence of biological medication and non - adherence in patients with AS in Egypt. Therefore, the aim of this study was to develop local epidemiologically cohort of AS Egyptian patients treated by biologic therapy to effectively evaluate outcomes and quantify benefits across clinical, quality of life and work outcomes.

\section{METHODS}

This prospective cohort study was performed from March 2018 to March 2020 on sixty -six consecutive patients with AS which represent patients with AS received biological treatment in Sharkia governorate (In Rheumatology and Rehabilitation department at Zagazig University Hospitals (ZUH) 26 patients and in insurance hospital in Al Sharqia Governorate 40 patients). Eligibility criteria included a diagnosis of AS according to the modified New York criteria [11] and an inadequate response or intolerance to at least one conventional treatment for at least 6 months. The exclusion criteria were as follows: age less than 16 years, cognitive dysfunction, cancer, stroke, tuberculosis or hepatitis and lost follow up in the last 6 months.

The study was done according to The Code of Ethics of the World Medical Association (Declaration of Helsinki) for studies involving humans. Zagazig University Institutional Review Board approval (Number 6492) and an informed consent was taken after explanation to the purpose of this study to all patients, Patients Characteristics included age, sex, education, occupation, health insurance, comorbidities, past medical history and family history were collected. Clinical data were recorded including disease duration, back pain onset, date of diagnosis, presence of AS features, pervious treatment, blood investigations and radiographs of sacroiliac joint and spine $\mathrm{X}$-rays and/or magnetic resonance images (MRI), and were collected for digitization. The Compliance Questionnaire on Rheumatology (CQR) [12] Self-reported questionnaire was used to evaluate medication adherence. This 19 -item questionnaire measures patients' agreement with certain statements through a four -point Likert scale, ranging from "strongly disagree" 
(scored as 1) to “strongly agree” (scored as 4). Final scores range from 0 (no adherence) to 100 (perfect adherence). The patients were grouped as adherent and non -adherent using a cut -off score of $60 \%$ according to previous studies [6]. Arabic translated version of CQR was used, the Arabic translation validated recently [13] with a modification to item 16 to fit our population. Treatment Response and Disease Activity evaluation: outcome measures were recorded at base line (first dose) of biologics, after 6 month and after 12 months to focus on biologic drugs adherence importance and highlighted outcome measurements and percentage of change

- Full clinical examination

- Laboratory investigation: CRP (C reactive protein), ESR (Erythrocyte sedimentation rate)

- Ankylosing Spondylitis Disease Activity Score (ASDAS) included CRP at $2 \mathrm{mg} / \mathrm{L}$ was used as the cutoff, but the ASDAS with ESR is shown as an alternative [14].

- Bath Ankylosing Spondylitis Functional Index (BASFI) [15].

- Bath Ankylosing Spondylitis Metrology Index (BASMI) [16].

- Ankylosing Spondylitis Quality of Life Index (ASQoL) [17] represent the impact of AS 'at present moment' it contains 18 yes/ no items. The total score ranges from 0 to 18 , with lesser scores denoting better AS -specific quality of life and differences of one to two points are clinically relevant

- The Work Productivity and Activity Impairment (WPAI) questionnaire adapted for SpA [18], it consists of six(yes/no) questions to assess employment status, work time missed either due to ankylosing spondylitis (hours), or due to other reasons (hours), actual work time (hours), the impact of ankylosing spondylitis on work productivity during work (0:10 point scale) and the impact of AS on outside work activities (0:10 point scale) for the last 7 days before questionnaire completion. Four scores are derived from the questions: percent absenteeism (work time missed), percent presenteeism (impairment at work), percent work productivity loss (overall work impairment due to absenteeism and presenteeism) and percent activity impairment (outside work activities). Higher scores indicate a higher level of impairment. [19]

Statistical analysis:The results were presented as mean and standard deviation (SD) for continuous variables and compared using the independent $\mathrm{T}$ test or Mann -Whitney test when comparing two groups while paired t test and paired Wilcoxon used when comparing different time in each group.

Categorical variables were shown as number and percentage and compared between groups through the Fisher Exact Test or Chi square when indicated. McNemmar test was used to compare between different times in each group. Percent of change in the least square (LS) mean for each outcome (ASQoL and WPAI domain scores) from baseline to 6 months and to 12 months was calculated.

\section{RESULTS}

Sixty six patients with AS were participated in the study. The patients' mean age was 31.9 (SD 6.5) with range $18-46$, as regarding to patient's sex, 49 (74.2\%) were males and 17 (25.8\%) were females. The mean education duration was 12.5 (SD 2.5) with range (8 -16) years. As far as professional occupation is concerned, 10 (15.2\%) were students, 17 (25.8\%) were unemployed or house wives at the time of the data collection and 39 (59\%) were employed also 32 cases (48.5) had health insurance, as shown in table 1.

Regarding clinical data, the mean disease duration was 27.45 (SD 4) month with range (6 - 48). Mean onset of symptoms till diagnosis was 24.4 (SD 4.5) with range (6-34 months). Family history was positive in 30 patients (45.5\%) and comorbidity (DM, HPT...etc.) were founded in 21 (31.8\%). Peripheral involvement had been noticed in 15 (22.7\%) of the cases, axial involvement in 19 (28.8\%) and both was in (48.5\%). Enthesitis, dactylitis, uvetis and psoriasis were founded in $(66.7 \%$, $19.7 \%, 30.0 \%$ and $7.6 \%$ respectively) and inflammatory bowel disease was in 11 (16.7\%) of the cases. Previous treatment was reported in 
60 cases $(90.1 \%)$ with mean duration 8.5 (SD 1.6) years.

In Table 1, comparison between adherent and non -adherent cases reveals that, a highly statistical significance decrease in mean age, mean disease duration, time onset of symptom till diagnosis and previous treatment duration in adherent cases compared to non - adherent. Also a highly statistical significance increase in mean education years, frequency of students and employed, frequency of cases had health insurance, frequency of +ve family history and frequency of uveitis among adherent cases compared to non - adherent.

The follow up of disease activity parameters at baseline, 6 \& 12 months were displayed in Table 2. No difference was found between adherent and non -adherent in all parameters at baseline. All parameters were decreased in adherent compared to non -adherent after 6 months but without statistical significance difference except in BASMI and was statistically decreases in adherent compared to non adherent at 12 months.

Table 3 showed the follow up of WPAI and ASQOL in patients at baseline, 6 \& 12 months. In WPAI there was no statistical significance difference between adherent cases and non adherent in overall work impairment and over all activity impairment at baseline. Both were decreased in adherent compared to non adherent after 6 months but without statistical significance difference and statistically decreases in adherent compared to non adherent at 12 months. ASQoL score was statistically decreased in adherent cases compared to non adherent at both 6 and 12 months.

Figure (1) revealed percent of change in different parameters from base line to 6 months in both adherent and non adherent cases and Figure (2) showed percent of change in different parameters from base line to 12 months in both adherent and non adherent cases. 
Table 1. Patient's Characteristics according to CQO results, the patients divided as an adherent and non-adherent

\begin{tabular}{|c|c|c|c|c|}
\hline Variable & $\begin{array}{c}\text { Total } \\
(\mathrm{n}=66)\end{array}$ & $\begin{array}{c}\text { Adherent } \\
(\mathrm{n}=30) \\
45.5 \%\end{array}$ & $\begin{array}{c}\text { Non adherent } \\
(\mathrm{n}=36) \\
54.5 \%\end{array}$ & \\
\hline Age (years) mean $\pm S D$ & $31.9 \pm 6.5$ & $27.4 \pm 4$ & $36.5 \pm 9$ & $<0.001 * * \wedge$ \\
\hline $\begin{array}{r}\text { Sex } m / f \quad n \\
(\%)\end{array}$ & $\begin{array}{c}49 / 17 \\
74.2 / 25.8\end{array}$ & $\begin{array}{c}22 / 8 \\
73.3 / 26.7\end{array}$ & $\begin{array}{l}27 / 9 \\
75 / 25\end{array}$ & $\begin{array}{l}0.88 \# \\
\text { NS }\end{array}$ \\
\hline Education (years) mean \pm SD & $12.5 \pm 2.5$ & $15 \pm 2$ & $10 \pm 5$ & $<0.001 * * \wedge$ \\
\hline $\begin{array}{c}\text { Occupation: Student } \mathrm{n}(\%) \\
\text { Not employed n (\%) }\end{array}$ & $10(15.2 \%)$ & $6(20 \%)$ & $\begin{array}{l}4(11.1 \%) \\
15(41.7 \%)\end{array}$ & $0.005^{* * \#}$ \\
\hline $\begin{array}{l}\text { Employed } \mathrm{n}(\%) \\
\text { Health insurance ves } \mathrm{n}(\%)\end{array}$ & $\begin{array}{c}39(59 \%) \\
32(485 \%)\end{array}$ & $\begin{array}{c}22(73.3 \%) \\
27(90 \%)\end{array}$ & $17(47.2 \%)$ & $<0.001 * * \#$ \\
\hline Disease duration (months $\pm \mathrm{SD}$ ) & $\begin{array}{c}32(40.5 \%) \\
27.45 \pm 4\end{array}$ & $24.8 \pm 5$ & $\begin{array}{l}5(13.9 \%) \\
32.1 \pm 3\end{array}$ & $<0.001 * * \wedge$ \\
\hline $\begin{array}{l}\text { Onset of symptom till diagnosis duration } \\
\text { (months) mean } \pm S D\end{array}$ & $24.4 \pm 4.5$ & $9.7 \pm 3$ & $21.7 \pm 6$ & $<0.001 * * \wedge$ \\
\hline Family history +vet n (\%) & $30(45.5 \%)$ & $18(60 \%)$ & $12(33.3 \%)$ & $0.03 * \#$ \\
\hline Comorbidities yes n (\%) & 21(31.8\%) & $12(40 \%)$ & $9(25 \%)$ & 0.19 NS\# \\
\hline Peripheral involvement, ever n (\%) & $15(22.7 \%)$ & $7(23.3 \%)$ & $8(22.2 \%)$ & \\
\hline Axial involvement $\mathrm{n}(\%)$ & $19(28.8 \%)$ & $8(26.7 \%)$ & $11(30.6 \%)$ & 0.94 NS\# \\
\hline Both peripheral and axial n (\%) & $32(48.5 \%)$ & $15(50 \%)$ & $17(47.2 \%)$ & \\
\hline Enthesitis, ever, n (\%) & $44(66.7 \%)$ & $21(70 \%)$ & $23(63.9 \%)$ & 0.60 NS\# \\
\hline Dactylitis, ever, n (\%) & $13(19.7 \%)$ & $5(16.7 \%)$ & $8(22.2 \%)$ & 0.57 NS\# \\
\hline Uveitis, ever, n (\%) & $20(30.3 \%)$ & $14(46.7 \%)$ & $6(16.7 \%)$ & $0.008 * * \#$ \\
\hline Psoriasis, ever, n (\%) & $5(7.6 \%)$ & $3(10 \%)$ & $2(5.6 \%)$ & $0.50 \mathrm{NS} \#$ \\
\hline Inflammatory bowel disease, ever, n (\%) & $11(16.7 \%)$ & $5(16.7 \%)$ & $6(16.7 \%)$ & 0.99 NS\# \\
\hline $\begin{array}{l}\text { Previous treatment duration months: } \\
\text { ( mean } \pm \text { SD) } \\
\mathrm{n}(\%)\end{array}$ & $\begin{array}{c}8.5 \pm 1.6 \\
60(90.1 \%)\end{array}$ & $\begin{array}{c}6 \pm 1.2 \\
21(70 \%)\end{array}$ & $\begin{array}{c}11 \pm 1.9 \\
29(80.5 \%)\end{array}$ & $\begin{array}{l}<\mathbf{0 . 0 0 1} * * \wedge \\
0.93 \mathrm{NS}\end{array}$ \\
\hline
\end{tabular}

SD: Standard deviation $\quad \wedge$ : Independent t test $\quad$ \#: Chi square test

NS: Non significant $(\mathrm{P}>0.05) \quad$ *: Significant $(\mathrm{P}<0.05) \quad * *$ : highly significant $(\mathrm{P}<0.01)$

Table 2. Follow up of disease activity parameters in patients measured at baseline, 6 and 12 months

\begin{tabular}{|c|c|c|c|c|c|c|c|c|c|}
\hline Parameters & \multicolumn{2}{|c|}{ Baseline } & \multirow[b]{2}{*}{$\mathbf{P !}$} & \multicolumn{2}{|c|}{ 6months } & \multirow[b]{2}{*}{$\mathbf{P !}$} & \multicolumn{2}{|c|}{12 months } & \multirow[b]{2}{*}{ P! } \\
\hline $\begin{array}{l}(\text { mean } \pm \text { SD) } \\
/(\%)\end{array}$ & $\begin{array}{c}\text { Adherent } \\
(n=30)\end{array}$ & $\begin{array}{c}\text { Non } \\
(n=36)\end{array}$ & & $\begin{array}{c}\text { Adherent } \\
(\mathrm{n}=30)\end{array}$ & $\begin{array}{c}\text { Non } \\
(n=36)\end{array}$ & & $\begin{array}{c}\text { Adherent } \\
(n=30)\end{array}$ & $\begin{array}{c}\text { Non } \\
(n=36)\end{array}$ & \\
\hline \multirow{2}{*}{$\begin{array}{l}\text { ASDAS } \\
\text { (CRP) }\end{array}$} & $3.91 \pm 2.14$ & $3.64 \pm 1.98$ & $\begin{array}{c}0.60 \\
\text { NS }\end{array}$ & $2.83 \pm 1.54$ & $3.26 \pm 1.93$ & $\begin{array}{c}0.33 \\
\text { NS }\end{array}$ & $1.96 \pm 1.44$ & $2.94 \pm 1.58$ & $0.01 *$ \\
\hline & \multicolumn{3}{|c|}{$\mathbf{P}^{\$}$ versus baseline } & $0.03 *$ & $0.41 \mathrm{NS}$ & & $<0.001 * *$ & $0.06 \mathrm{NS}$ & \\
\hline \multirow[t]{2}{*}{$\begin{array}{l}\text { ASDAS } \\
\text { (ESR) }\end{array}$} & $3.87 \pm 2.75$ & $4.18 \pm 1.94$ & $\begin{array}{c}0.59 \\
\text { NS }\end{array}$ & $2.88 \pm 2.14$ & $3.65 \pm 2.13$ & $\begin{array}{l}0.71 \\
\text { NS }\end{array}$ & $1.81 \pm 1.08$ & $3.32 \pm 1.44$ & $<0.001 * *$ \\
\hline & \multicolumn{3}{|c|}{$\mathbf{P}^{\$}$ versus baseline } & $0.04 *$ & $0.27 \mathrm{NS}$ & & $<0.001 * *$ & $0.07 \mathrm{NS}$ & \\
\hline \multirow[t]{2}{*}{$\begin{array}{l}\text { BASFI } \\
(0-10)\end{array}$} & $4.11 \pm 2.42$ & $4.65 \pm 2.69$ & $\begin{array}{c}0.40 \\
\text { NS }\end{array}$ & $3.54 \pm 2.12$ & $4.18 \pm 2.37$ & $\begin{array}{l}0.26 \\
\text { NS }\end{array}$ & $2.74 \pm 1.94$ & $4.93 \pm 2.53$ & $<0.001 * *$ \\
\hline & \multicolumn{3}{|c|}{$\mathbf{P}^{\$}$ versus baseline } & $0.34 \mathrm{NS}$ & $0.43 \mathrm{NS}$ & & $0.02 *$ & $0.65 \mathrm{NS}$ & \\
\hline \multirow[t]{2}{*}{$\begin{array}{l}\text { BASMI } \\
(0-10)\end{array}$} & $4.75 \pm 2.29$ & $5.06 \pm 2.35$ & $\begin{array}{c}0.59 \\
\text { NS }\end{array}$ & $4.17 \pm 2.31$ & $5.06 \pm 2.35$ & $0.02 *$ & $3.52 \pm 1.74$ & $5.86 \pm 2.65$ & $<0.001 * *$ \\
\hline & \multicolumn{3}{|c|}{$\mathbf{P}^{\$}$ versus baseline } & $0.33 \mathrm{NS}$ & $1 \mathrm{NS}$ & & $0.02 *$ & $0.18 \mathrm{NS}$ & \\
\hline
\end{tabular}

ESR: erythrocyte sedimentation rate, CRP: the C -reactive protein, ASDAS: Ankylosing Spondylitis Disease Activity Score, BASFI: Bath Ankylosing Spondylitis Functional Index, BASMI: Bath Ankylosing Spondylitis Metrology Index.

SD: Standard deviation $\quad$ ! Mann Whitney test \$: Paired Wilcoxon test

NS: Non significant $(\mathrm{P}>0.05) \quad$ *: Significant $(\mathrm{P}<0.05) \quad * *$ : highly significant $(\mathrm{P}<0.01)$ 
Table 3. Follow up of wpai and asqol in patients measured at baseline, 6 and 12 months

\begin{tabular}{|c|c|c|c|c|c|c|c|c|c|}
\hline \multirow{2}{*}{$\begin{array}{l}\text { Paramet } \\
\text { ers } \\
\text { (mean } \pm S \\
\text { D) } \\
/ \mathbf{N}(\%)\end{array}$} & \multicolumn{2}{|c|}{ Baseline } & \multirow{2}{*}{$\mathbf{P}$} & \multicolumn{2}{|c|}{ 6months } & & \multicolumn{2}{|c|}{ 12months } & \\
\hline & $\begin{array}{c}\text { Adhere } \\
\text { nt } \\
(n=30)\end{array}$ & $\begin{array}{c}\text { Non } \\
(n=36)\end{array}$ & & $\begin{array}{c}\text { Adhere } \\
\text { nt } \\
(n=30)\end{array}$ & $\begin{array}{c}\text { Non } \\
(n=36)\end{array}$ & & $\begin{array}{c}\text { Adhere } \\
\text { nt } \\
(n=30)\end{array}$ & $\begin{array}{c}\text { Non } \\
(n=36)\end{array}$ & \\
\hline $\begin{array}{l}\text { WPAI } \\
\text { (last } 7 \\
\text { days) }\end{array}$ & $\begin{array}{c}(n=22) \\
9(40.9 \\
\%)\end{array}$ & $\begin{array}{c}(n=17) \\
7(41.2 \\
\%)\end{array}$ & $\begin{array}{c}0.99 N \\
\text { S\# }\end{array}$ & $\begin{array}{c}(n=22) \\
6(27.3 \\
\%)\end{array}$ & $\begin{array}{c}(n=17) \\
6(35.3 \\
\%)\end{array}$ & $\begin{array}{c}0.59 \mathrm{NS} \\
\#\end{array}$ & $\begin{array}{c}(n=22) \\
3(18.2 \\
\%)\end{array}$ & $\begin{array}{c}(n=17) \\
7(41.2 \% \\
)\end{array}$ & $0.04 * \#$ \\
\hline $\begin{array}{l}\text {-Overall } \\
\text { work } \\
\text { impairme } \\
\text { nt }\end{array}$ & \multicolumn{3}{|c|}{$\mathbf{P}(\mathrm{C}$ versus baseline } & $\begin{array}{c}0.37 \\
\text { NS }\end{array}$ & $0.93 \mathrm{NS}$ & & $0.01 *$ & $1 \mathrm{NS}$ & \\
\hline \multirow{2}{*}{$\begin{array}{l}\text { - Overall } \\
\text { activity } \\
\text { impairme } \\
\text { nt }\end{array}$} & $\begin{array}{c}10(33.3 \\
\%)\end{array}$ & $\begin{array}{c}11(30.5 \\
\%)\end{array}$ & $\begin{array}{c}0.81 N \\
\text { S\# }\end{array}$ & $\begin{array}{c}7(23.3 \\
\%)\end{array}$ & $\begin{array}{c}13(36.1 \\
\%)\end{array}$ & $\begin{array}{c}0.26 \mathrm{NS} \\
\#\end{array}$ & $\begin{array}{c}5(16.7 \\
\%)\end{array}$ & $\begin{array}{c}14(38.9 \\
\%)\end{array}$ & $0.04^{* \#}$ \\
\hline & \multicolumn{3}{|c|}{$\mathbf{P}(\mathbb{C}$ versus baseline } & $\begin{array}{c}0.39 \\
\text { NS }\end{array}$ & $0.61 \mathrm{NS}$ & & $0.03^{*}$ & $0.46 \mathrm{NS}$ & \\
\hline \multirow[t]{2}{*}{$\begin{array}{l}\text { ASQOL } \\
(0-18)\end{array}$} & $\begin{array}{c}13.05 \pm 3 \\
.6\end{array}$ & $\begin{array}{c}11.7 \pm \\
3.2\end{array}$ & $\begin{array}{c}0.11 \mathrm{~N} \\
\mathrm{~S}^{\wedge}\end{array}$ & $\begin{array}{c}10.3 \pm 2 \\
74\end{array}$ & $\begin{array}{c}12.5 \pm 2 \\
29\end{array}$ & $\begin{array}{c}<0.001 * \\
* \wedge\end{array}$ & $8.1 \pm 3.1$ & $\begin{array}{c}14.61 \pm 2 . \\
30\end{array}$ & $\begin{array}{c}<0.001 * \\
* \wedge\end{array}$ \\
\hline & \multicolumn{3}{|c|}{ P@ versus baseline } & $\begin{array}{c}0.002 * \\
*\end{array}$ & $0.23 \mathrm{NS}$ & & $\begin{array}{c}<0.001 \\
* *\end{array}$ & $\begin{array}{c}<0.001 * \\
*\end{array}$ & \\
\hline
\end{tabular}

WPAI: Work Productivity and Activity Impairment, ASQoL: Ankylosing Spondylitis Quality of Life Index.

SD: Standard deviation $\quad \wedge$ : Independent t test \#: Chi square test

@: Paired t test $\quad$ (C): McNenmmar test

NS: Non significant $(\mathrm{P}>0.05) \quad$ *: Significant $(\mathrm{P}<0.05) \quad * *$ : highly significant $(\mathrm{P}<0.01)$

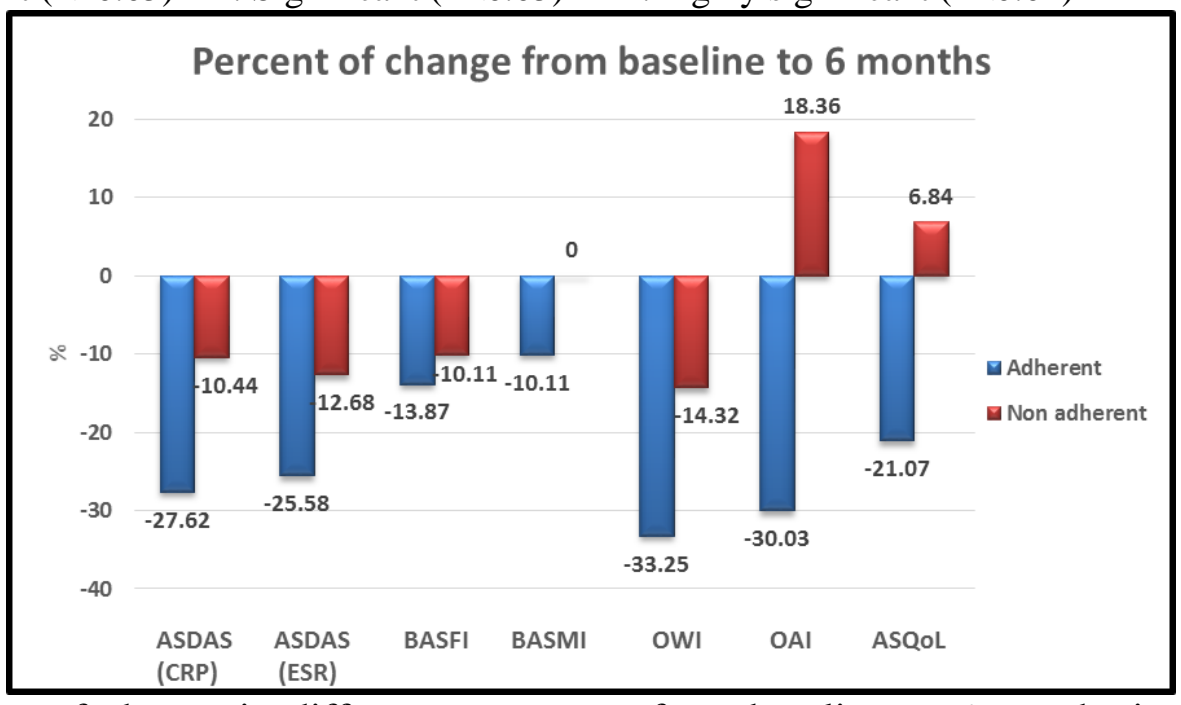

Figure 1. Percent of change in different parameters from baseline to 6 months in adherent \& non adherent cases.

ESR: erythrocyte sedimentation rate, CRP: the C -reactive protein, ASDAS: Ankylosing Spondylitis Disease Activity Score, BASFI: Bath Ankylosing Spondylitis Functional Index, BASMI: Bath Ankylosing Spondylitis Metrology Index, OWI: Overall work impairment, OAI: Overall activity impairment, ASQoL: Ankylosing Spondylitis Quality of Life Index. 


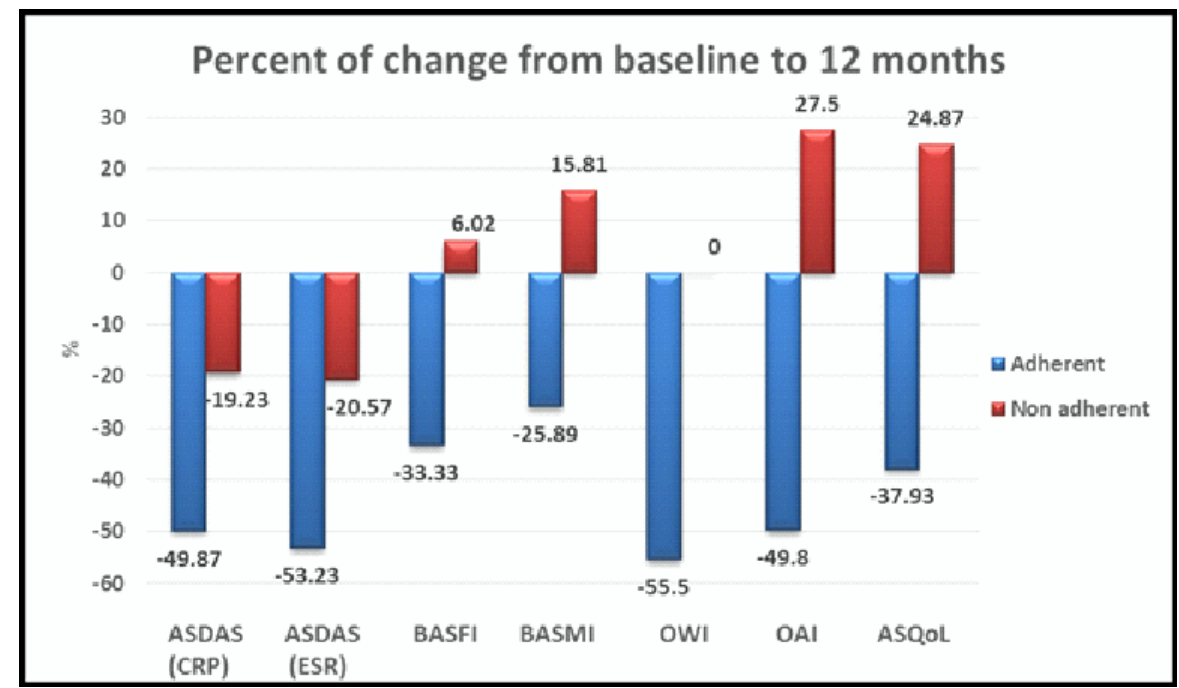

Figure 2. Percent of change in different parameters from baseline to 12 months in adherent \& non adherent cases.

ESR: erythrocyte sedimentation rate, CRP: the C -reactive protein, ASDAS: Ankylosing Spondylitis Disease ActivityScore,BASFI: Bath Ankylosing Spondylitis Functional Index, BASMI: Bath Ankylosing Spondylitis Metrology Index, OWI: Overall work impairment, OAI: Overall activity impairment, ASQoL: Ankylosing Spondylitis Quality of Life Index.

\section{DISCUSSION}

In rheumatic diseases, the majority of compliance studies have been performed in RA it showed that the lack of adherence was related to a longer disease duration, higher side effects and belief about the necessity of treatment[ 20]. AS develops as a complex immune reaction interactions between genetic background and environmental factors, endocrinal abnormity and microbial infection. Only a few studies investigated the association between biologic drugs adherence and AS outcome measures and work productivity

Furthermore, it is reasonable to plan a time limited treatment for some patients who are most likely to benefit from a particular treatment is crucial in delivering cost effective care, for that our study re -evaluate the patients after 6 months then after one year.

Arturi et al [6 ], used a self-administered questionnaire CQR to evaluate compliance with pharmacological treatment in AS, percentage of adherent vs. non -adherent for AS was (25.4\% vs. $174.5 \%)$, non -adherent AS patients for CQR were old age, long disease duration and had worse depression scores; the differences did not reach statistical significance. CQR scores were higher in patients receiving anti -TNF treatment, but differences did not reach statistical significance

The present study focus on biological medication adherence using CQR questionnaire showed $45.5 \%$ adherence versus $55.5 \%$ non adherent patient. Characteristic analyzed showed no significant relationship between sex, comorbidities, and type of involvement, frequency of enteritis, dactilitis, psoriasis, inflammatory bowel disease and frequency of previous treatment intake to adherence. While adherence was significantly more in students, employed, +ve family history and cases had uveitis. Also the highly significant difference in favor to adherent patients showed younger age, shorter disease duration, and short time onset of symptom till diagnosis, more education, health insurance and short time of previous treatment. Collection of these factors could help us to modulate our strategies to improve adherence that are essentially based on patient selection and health education. 
In contrast of our study Tolu et al [7] studied medication adherence in 99 Turkish patients with ankylosing spondylitis (AS). Adherence to anti -rheumatic drugs was elicited using the Compliance Questionnaire on Rheumatology (CQR) and analyzed the related factors for non -adherence the results showed that non adherence was reported in 64 patients (64.6\%). Beliefs about medicines and illness perception were found to predict adherence more strongly than socio -demographic or clinical factors in Turkish patients. While demographic, clinical or psychological factors showed no significant relationship to adherence, except for disease duration. The difference between the present study and the previous two studies all use CQR in percentage of adherence may be due to specification of type AS patient by eligibility criteria written in patient and methods and specification of biological medication

A recent Chinese study done by $\mathrm{Ji}$ et al [8] evaluate effectiveness of subcutaneous tumor necrosis factor inhibitors (TNFi ) in a total of 804 patients with AS, the mean duration of TNFi treatment was $6.9 \pm 3.2$ months. Reductions in ASDAS were more significantly in TNFi users than in nonusers at 3, 6 and 12 months. Similarly, the improvement in BASFI was more significantly in users than in nonusers at 3, 6 and 12 months. BASMI increased in nonusers at 6 and 12 months, but did not change in users both times. At 12 months, changes in BASMI were more significantly in nonusers than in users.

The study of Ji et al [8] in agreement of our results of disease outcome measures although we highlighted the adherence of biological medication available in Egypt and health insurance services in general not TNFi only also evaluation was done at base line then after 6 and 12 months. Reductions in ASDAS were significantly greater in adherent than in non adherent ASDAS CRP,and ASDAS ESR were significant decrease at 6 months compared to baseline and highly significant decreased at 12 months compared to baseline and significant decrease at 12 months compared to 6 months. BASFI \& BASMI were statistically decrease at
12 months compared to baseline. More over in our study the percentage of insurance adherent vs. non -adherent ( $90 \%$ vs.13.9\%) showed higher percentage in adherent as the majority of patients may not be able to pay the high cost of biological therapies for a prolonged time from our study adherent patients gain more benefit as regard all out come measures especially BASMI at 6 months and one year in addition non -adherent (60\% cut -off ) gain improvement and decreased activity even without statistical significance with agreement of $\mathrm{Ji}$ et al[8] study concluded that TNF controlled AS disease activity and improve the physical function of patients, even in those who decrease or discontinue TNFis may preserve spinal mobility as evaluated by the BASMI..

Health -related quality of life (HRQoL) reflect the functional effect of the diease and its treatment, as recognized by the patient. Impaired physical function and disease activity, concomitant with AS, have significant impact on HRQoL [21].

The present study addressed HRQoL as the primary outcome using the ASQoL specific questionnaire for AS which focus on mobility and the capability for performance of daily activities, our results showed that no difference was found between adherent cases and non adherent at baseline. There was a statistically significant decreases in ASQOL score among adherent cases compared to non -adherent at both 6 and 12 months. In non - adherent cases no difference was found between base line and 6 months but there was a statistical significance increase in ASQoL score at 12 months. In adherent cases ASQoL statistically decreased at 6 months compared to baseline and significant decreased at 12 months compared to baseline and statistically decrease at 12 months compared to 6 months.

Y1lmaz et al. [22] concluded that more severe functional disability resulted in worse QoL confirmed by high correlation of ASQoL with parameters of AS activity as ASDAS -ESR, ASDAS -CRP, BASMI and BASFI scores. In agreement of our results Sallam et al [10] 
evaluate health -related quality of life (HRQoL) and related factors in Egyptian ankylosing spondylitis (AS) patients using ASQoL questionnaire. The results showed that AS patients had significant poorer QoL than the controls, especially with high disease activity, functional disability, many peripheral joint affection and decreased spinal mobility in Egyptian patients.

Work disability involve up to $30 \%$ of ankylosing spondylitis (AS) patients compared to the general population, AS patients report decreased employment and more absenteeism [23]. One earlier systematic review by van der Burg et al [9] enclose nine trials based on single group, pre -therapy and post -therapy studied the effect of biological treatment on three work outcomes: work status, absenteeism and presenteeism. It resulted that presenteeism decreased by $17 \%-29 \%$ and absenteeism decreased by $8.7-22.3$ days over a period of 12 months after beginning of biological therapy.

In agreement of van der Burg et al [9] in the present study most of our patients have physically demanding jobs, WPAI evaluated by overall work impairment and over all activity impairment there was no statistical significance difference between adherent cases and non adherent in at baseline. Work impairment and over all activity impairment were decreased in adherent cases compared to non -adherent at 6 months without significant difference while in 12 months it became significant. In non adherent cases no difference was found all through follow up, while in adherent cases frequency of overall work impairment and over all activity impairment was decreased in 6 months without statistical difference but in 12 months comparing to baseline a statistically significant decrease was founded with percent of reduction in both more than 50\%

Shim et al [24] studied the effect of biological therapy on work outcomes in patients with axial spondyloarthritis: concluded that there is consistent evidence, across many studies, that biological therapy significantly and effectively upgrade work productivity and decrease activity impairment. The main limitation of our study is its low sample size. However, our sample size remains consistent with previous validation studies, evaluation of drugs therapy without evaluation of rehabilitation program and short time of follow up

\section{CONCLUSSION}

Biological therapy adherence leads to control of disease activity confirmed by percentage of change in activity parameters after 6 months and highly significant change after 12 months of follow up especially BASMI in addition to improvements of health - related quality of life and work productivity and activity impairment even in non - adherent who gain partial improvement.

Declaration of interest: Nothing to declare.

Funding information: Nothing to declare. REFERENCES

1 -Zhu W, He X, Cheng K, Zhang L, Chen D, Wang X, Qiu G, Cao X, Weng X. Ankylosing spondylitis: etiology, pathogenesis, and treatments. Bone Res.. 2019 Aug 5;7(1):1-6.

2- van der Heijde D, Ramiro S, Landewé R, Baraliakos X, Van den Bosch F, Sepriano A, Regel A, Ciurea A, Dagfinrud H, Dougados M, van Gaalen F. 2016 update of the ASASEULAR management recommendations for axial spondyloarthritis. Ann. Rheum. Dis. 2017 Jun 1;76(6):978-91.

3 - Sieper J, Poddubnyy D. Axial spondyloarthritis. The Lancet. 2017 Jul 1;390(10089):73-84.

4 - Dobbels F, Damme-Lombaert RV, Vanhaecke J, Geest SD. Growing pains: Non-adherence with the immunosuppressive regimen in adolescent transplant recipients. Pediatr. Transplant. 2005 Jun;9(3):381-90.

5 - Smolen JS, Gladman D, McNeil HP, Mease PJ, Sieper J, Hojnik M, Nurwakagari P, Weinman J. Predicting adherence to therapy in rheumatoid arthritis, psoriatic arthritis or ankylosing spondylitis: a large cross-sectional study. RMD open. 2019 Jan 1;5(1).

6- Arturi P, Schneeberger EE, Sommerfleck F, Buschiazzo E, Ledesma C, Cocco JA, Citera G. Adherence to treatment in patients with ankylosing spondylitis. Clin. Rheumatol.. 2013 Jul 1;32(7):1007-15.

7 - Tolu S, Rezvani A, Karacan İ, Bugdaycı D, Küçük HC, Bucak ÖF. Self-Reported Medication Adherence in Patients With 
Ankylosing Spondylitis: The Role of Illness Perception and Medication Beliefs. Arch. Rheumatol .2020; 35 (x): i-xi. Arch. Rheumatol. ii occupational activities, resulting in considerable socioeconomic burden for patients and society.;2:2..

8 - Ji X, Wang Y, Hu Z, Ma Y, Man S, Li K, et al. Effectiveness of Subcutaneous Tumor Necrosis Factor Inhibitors in Patients With Ankylosing Spondylitis: A Real-World Prospective Observational Cohort Study in China. Front. Pharmacol. 2019;10:1476.

9- van der Burg LR, ter Wee MM, Boonen A. Effect of biological therapy on work participation in patients with ankylosing spondylitis: a systematic review. Ann. Rheum. Dis. 2012 Dec 1;71(12):1924-33.

10- Sallam RA, Elbahnasawy AS. Health related quality of life (HRQoL) in ankylosing spondylitis patients: Relation to clinical features, disease activity and radiographic damage. Egypt. Rheumatol... 2020 Feb 17.

11- Linden SV, Valkenburg HA, Cats A. Evaluation of diagnostic criteria for ankylosing spondylitis. Arthritis Rheumatol. 1984 Apr;27(4):361-8.

12- de Klerk E, Van der Heijde D, Van der Tempel $\mathrm{H}$, Van Der Linden S. Development of a questionnaire to investigate patient compliance with antirheumatic drug therapy. Rheumatology. 1999 Dec 1;26(12):2635-41.

13- Ziade NR. Karam GA , Salloum N and Zoghb M: Transcultural Adaptation and Validation of the Arabic Version of the Compliance Questionnaire for Rheumatology September 2020 ASOR (ISSN: 2581-8635).

14 - Machado P, Navarro-Compán V, Landewé R, van Gaalen FA, Roux C, van der Heijde D. Brief Report: Calculating the Ankylosing Spondylitis Disease Activity Score If the Conventional C-Reactive Protein Level Is Below the Limit of Detection or If HighSensitivity C-Reactive Protein Is Used: An Analysis in the DESIR Cohort. A\& R 2015 Feb;67(2):408-13.

15 - Calin A, Garrett S, Whitelock H, Kennedy LG, O'hea J, Mallorie P, Jenkinson T. A new approach to defining functional ability in ankylosing spondylitis: the development of the Bath Ankylosing Spondylitis Functional Index. Rheumatology 1994 Dec 1;21(12):2281-5.
16 - Jenkinson TR, Mallorie PA, Whitelock HC, Kennedy LG, Garrett SL, Calin A. Defining spinal mobility in ankylosing spondylitis (AS). The Bath AS Metrology Index. Rheumatology. 1994 Sep 1;21(9):1694-8.

17 - Doward L, Spoorenberg A, Cook SA, Whalley D, Helliwell PS, Kay LJ, McKenna SP, Tennant A, van der Heijde D, Chamberlain MA. Development of the ASQoL: a quality of life instrument specific to ankylosing spondylitis. Ann. Rheum. Dis 2003 Jan 1;62(1):20-6.

18 - Reilly MC, Gooch KL, Wong RL, Kupper H, Van der Heijde D. Validity, reliability and responsiveness of the Work Productivity and Activity Impairment Questionnaire in ankylosing spondylitis. Rheumatology. 2010 Apr 1;49(4):812-9.

19 - Phang JK, Kwan YH, Fong W, Tan CS, Lui NL, Thumboo J, Leung YY. Validity and reliability of Work Productivity and Activity Impairment among patients with axial spondyloarthritis in Singapore. Int $\mathrm{J}$ Rheum Dis . 2020 Apr;23(4):520-5..

20 - van den HOOGEN FH, BENRAAD B, HEKSTER YA, van LANKVELD WI. Adherence rates and associations with nonadherence in patients with rheumatoid arthritis using disease modifying antirheumatic drugs. Rheumatology. 2009 Oct 1;36(10):2164-70.

21 - Rosenbaum JT, Pisenti L, Park Y, Howard RA. Insight into the quality of life of patients with ankylosing spondylitis: real-world data from a US-based life impact survey. RHEUMATOL THER.. 2019 Sep 1;6(3):353-67.

22 Yılmaz Ö, Tutoğlu A, Garip Y, Özcan E, Bodur H. Health-related quality of life in Turkish patients with ankylosing spondylitis: impact of peripheral involvement on quality of life in terms of disease activity, functional status, severity of pain, and social and emotional functioning. Rheumatol. Int 2013 May 1;33(5):1159-63.

23 - Ramonda R, Marchesoni A, Carletto A, Bianchi G, Cutolo M, Ferraccioli G, Fusaro E, De Vita S, Galeazzi M, Gerli R, MatucciCerinic M. Patient-reported impact of spondyloarthritis on work disability and working life: the ATLANTIS survey. Arthritis Res. Ther. 2016 Dec;18(1):1-7. 
24 - Shim J, Jones GT, Pathan EM, Macfarlane GJ. Impact of biological therapy on work outcomes in patients with axial spondyloarthritis: results from the British Society for Rheumatology
Biologics Register (BSRBR-AS) and metaanalysis Ann. Rheum. Dis. 2018 Nov 1;77(11):1578-84.

\section{Cite This Article}

youssef, M., el rafey, D. Impact of biologics drugs adherence on treatment outcomes and work productivity of Al Sharqia Governorate patients with Ankylosing Spondylitis. Zagazig University Medical Journal, 2021; (104-

114): -. doi: 10.21608/zumj.2020.48238.1993 